\title{
EL RECONOCIMIENTO DE DIVORCIOS EXTRANJEROS: UNA VISIÓN COMPARATIVA ENTRE EL RÉGIMEN LATINOAMERICANO Y EUROPEO: APUNTES DE LA JURISPRUDENCIA PERUANA EN EL RECONOCIMIENTO DE DIVORCIOS NO JUDICIALES
}

\author{
RECOGNITION OF FOREIGN DIVORCE: A COMPARATIVE VISION \\ BETWEEN THE LATIN AMERICAN AND EUROPEAN SYSTEMS: NOTES \\ FROM THE PERUVIAN JURISPRUDENCE IN THE RECOGNITION OF \\ NO JUDICIAL DIVORCES
}

Carmen Julia Cabello Matamala ${ }^{1}$

\section{Resumen:}

El presente artículo aborda un tema de creciente incidencia en los poderes judiciales; esto es, el reconocimiento de sentencias extranjeras, ello en razón a los masivos desplazamientos migratorios que se producen actualmente por diversos factores, originando un gran impacto económico, social, jurídico y en las relaciones personales de los implicados especialmente en el ámbito familiar. En este tema, cabe resaltar particularmente, el relativo a la homologación de divorcios notariales y administrativos, cuya regulación en las diversas legislaciones civiles viene extendiéndose en Iberoamérica, pero que sin embargo, no reciben similar apertura en su tratamiento en el Derecho Internacional Privado para efecto de su reconocimiento.

\section{Palabras clave}

Movimientos migratorios, exequátur, homologación divorcios notariales, divorcios administrativos.

\section{Abstract}

This article approaches a topic of increasing incidence in the judiciary system that is the recognition of foreign sentences because of the massive migratory movements currently produced by several factors causing a great economic, social, legal impact

Jueza Suprema (P) de la Corte Suprema del Perú. Profesora de la Pontificia Universidad Católica del Perú. Doctora en Derecho por la PUCP. Egresada Curso Iberoamericano de especialización Escuela Judicial Consejo General del Poder Judicial de España 2014. 
and in the relationships of the personnel involved in the family. In this topic is worth noting, the standarization of notary and administrative divorces, whose regulation in the civil laws is spreading in Latin America, although they do not receive similar recognition in the private international law.

\section{Key Words}

Migration, exequatur, standarization of notary divorces, administrative divorces.

\section{INTRODUCCIÓN}

Es en este contexto que les propongo abordar un tema cuya incidencia es creciente en los poderes judiciales, consecuencia del movimiento migratorio incesante de sur a norte, de este a oeste, que encuentra hoy en Latinoamérica un actor protagónico, desplazamientos afectados por los vertiginosos cambios económicos, sociales y culturales, que inciden también en la vida familiar y por ello, en el estatuto personal de sus nacionales.

Trataremos en esta ocasión el reconocimiento de sentencias extranjeras de divorcio; para ello, abordaremos los siguientes temas:

I. La relevancia del tratamiento de la competencia internacional.

II. Tutela Judicial Internacional efectiva: Competencia judicial directa e indirecta.

III. Incidencia de exequatur de divorcio.

IV. Modelos de reconocimiento a nivel latinoamericano y europeo.

V. Apuntes de la jurisprudencia peruana sobre el reconocimiento de divorcios no judiciales, su perspectiva desde Iberoamérica.

\section{I. ¿POR QUÉ ES RELEVANTE EL TRATAMIENTO DE LA COMPETENCIA JUDICIAL INTERNACIONAL?}

DiegoFernández Arroyoa propósitodelimpactoeconómicodelaglobalización comentará: "La integración de los mercados y la internacionalización de la vida exigen respuestas adecuadas de los ordenamientos jurídicos. Entre ellas, el establecimiento de unos criterios básicos para la distribución de la competencia judicial, fundados en la razonabilidad, la concurrencia de foros 
y el respeto de los derechos fundamentales, deben concitar una atención privilegiada" 2

Podemos observar en esta última década que temas, que muchas veces sólo tenían relevancia académica en el ámbito del Derecho Internacional Privado, reclaman una creciente atención, por su incidencia en la realidad y la relevante complejidad que adquieren por el desarrollo social o tecnológico.

Advertimos situaciones familiares que pueden presentarse hoy en diversos lugares del mundo; apreciamos, por ejemplo, en la jurisprudencia española, sus respuestas en los casos de reconocimiento de sentencias extranjeras de divorcio repudio, como también en la peruana a partir del reconocimiento de divorcios administrativos o notariales, o la diversidad de posiciones en relación a los reconocimientos de filiaciones establecidas por medios paralelos, los casos de reclamación e impugnación de estado filial ante la evidencia biológica determinada por pruebas científicas como el ADN, que nos conducen a cuestionarnos frente a los avances científicos y su impacto en la filiación internacional, los paraísos procreativos y las prácticas de inseminación artificial, fecundación in vitro, gestación por subrogación, y sus efectos filiatorios, homologación de resoluciones de cambio de sexo, la adopción internacional heterosexual y homosexual, la restitución internacional de menores, entre otros muchos.

Temas contemporáneos como los planteados son materia de un tratamiento legislativo internacional diverso, que pueden importar en los hechos durante el proceso de cognición o de reconocimiento, la afectación del denominado orden público internacional del Estado receptor, el mismo que puede comprenderse con cierta flexibilidad y con ello permitir que esta noción asuma contornos inciertos, preocupantes si estos permiten extender subliminal o expresamente posiciones foristas.

Por ello, el conflicto de leyes -tema central de atención del Derecho Internacional Privado- ha sido desplazado por la atención que vienen reclamando los aspectos de Derecho Procesal Civil internacional y particularmente los referidos a la competencia, considerado la vía de acceso a la tutela de los derechos que se peticionen.

Fernández Arroyo, Diego (2008) Aspectos esenciales de la competencia judicial internacional en vistas de su reglamentación interamericana. Disponible en internet: http://www.oas.org/dil/esp/293-326\%20Diego\%20Fern\%C3\%A1ndez\%20A.\%20def.BIS.pdf Consultado el 20 de agosto de 2015. 
Al respecto, la Cometencia Judicial internacional, es definida por Aguilar Benitez como "Las normas reguladoras que establecen en qué condiciones, bajo qué requisitos, pueden conocer los órganos jurisdiccionales de un Estado de los problemas que se suscitan en las relaciones que aparecen conectadas con más de un ordenamiento jurídico". ${ }^{3}$

La función básica de las normas de competencia judicial internacional (CJI) es determinar si los tribunales de un Estado son o no competentes para conocer de un asunto o litigio internacional; esto es, de aquellos que presentan vínculos con otros Estados. Ello determina en un proceso planteado el examen de los criterios atributivos de comp etencia, y en los futuros, proporciona la necesaria predictibilidad, a fin de que los potenciales usuarios judiciales puedan prever de acuerdo al contenido de las normas de CJI ante qué tribunales estatales podrán acudir a solicitar tutela jurisdiccional internacional.

Incluso algunos podrán sostener, que la litigiocidad internacional en materia patrimonial se viene desplazando crecientemente a la solución de conflictos en el ámbito arbitral, hecho cierto; sin embargo, lo jurisdiccional reserva su exclusividad a las relaciones personales transfronterizas tanto a nivel de la competencia judicial directa como en la indirecta, cuando pretenden se declaren los derechos familiares o el reconocimiento de los aludidos divorcios, filiaciones, adopciones, etc. En tal sentido, consideramos fundamental enfocar este tema competencial desde su perspectiva constitucional como derecho fundamental.

\section{TUTELA JUDICIAL INTERNACIONAL EFECTIVA}

Como puede apreciarse, la tutela judicial efectiva, derecho fundamental de todo ciudadano, se presta de dos formas en las relaciones con elemento extranjero:

- A través de un proceso de cognición en el foro, en el que se solicita del juez nacional una resolución mediante la que declare un derecho, constituya o modifique una relación, o imponga una prestación, a la que denomina tutela por declaración; o

- A través del reconocimiento en el foro de la autoridad de la resolución adoptada por un tribunal extranjero declarando ese derecho,

Aguilar Benitez de Lugo, Mariano (2002) Lecciones de Derecho Procesal Civil Internacional, Universidad de Sevilla, Sevilla, p. 19. 
constituyendo o modificando esa relación, o imponiendo esa prestación, tutela por reconocimiento. ${ }^{4}$

Podemos concluir en estos aspectos generales, que la tutela judicial internacional por declaración como la de reconocimiento tienen como principio rector la tutela efectiva de los derechos de los ciudadanos en condiciones de igualdad entre nacionales o extranjeros que las ejerciten, es la conjunción de ambas a nivel internacional la que posibilita su concreción, su efectividad, de ahí su necesaria vinculación, los litigantes parte de una relación jurídica internacional persiguen que la justicia tutele sus derechos, que a través de sus sentencias son declarados, constituidos o condenados y que sus disposiciones se cumplan en las esferas territoriales necesarias; de no serlo, sus derechos aparecen defraudados. La globalización acelera la internacionalización de las relaciones jurídicas y la necesidad de satisfacción de estas expectativas necesarias. El respeto de las competencias, el debido proceso, la no afectación de los derechos fundamentales, son los postulados que imperan cada vez más en la orbe como pilares de la institucionalidad en los Estados democráticos, lo que debe generar la necesaria confianza y fortalecer los niveles de cooperación entre los Estados, a fin de procurar en principio el acceso y tutela jurisdiccional y con ello favorecer la tutela y protección de los derechos humanos.

\section{INCIDENCIA DE EXEQUATUR DE DIVORCIO}

Como se ha señalado, el tratamiento del reconocimiento de sentencias extranjeras de divorcio conjuga el interés académico propio de la especialidad así como el de su importante incidencia.

Afirmación que verificamos en el sistema judicial peruano, por ejemplo, al examinar el creciente número de solicitudes de reconocimiento de sentencias extranjeras de divorcio, que se vienen presentando en las Salas Superiores de la especialidad de familia de la Corte Superior de Justicia de Lima, la de mayor carga procesal en el Perú.

A continuación, citaremos algunas cifras estadísticas, que permiten mostrar en la experiencia peruana, en el transcurso de 20 años la progresión de solicitudes de reconocimiento de sentencias extranjeras en su mayoría de divorcio, la que se ha incrementado de $0.29 \%$ hasta superar actualmente

\footnotetext{
Virgos Soriano, Miguel (2007) Derecho Procesal Civil Internacional. Litigación internacional. Civitas, Madrid.
} 
el $20 \%$ de las causas de la Sala Superior de la especialidad de Familia en el Distrito Judicial de Lima, ya que de acuerdo a la ley procesal civil peruana la competencia para el conocimiento en primera instancia de las solicitudes de exequatur corresponden a las Salas Superiores y en revisión a la Sala Civil permanente y transitoria de la Corte Suprema.

Así, puede destacarse además que la mayor incidencia en el crecimiento se observa desde el 2006 en los últimos 7 años, coincidentes con el crecimiento económico que presenta el país 5 .

\section{INCIDENCIA DE EXEQUATUR EN DERECHO DE FAMILIA $1^{\circ}$ Sala Especializada de Familia de la Corte Superior de Lima $1993-2013$}

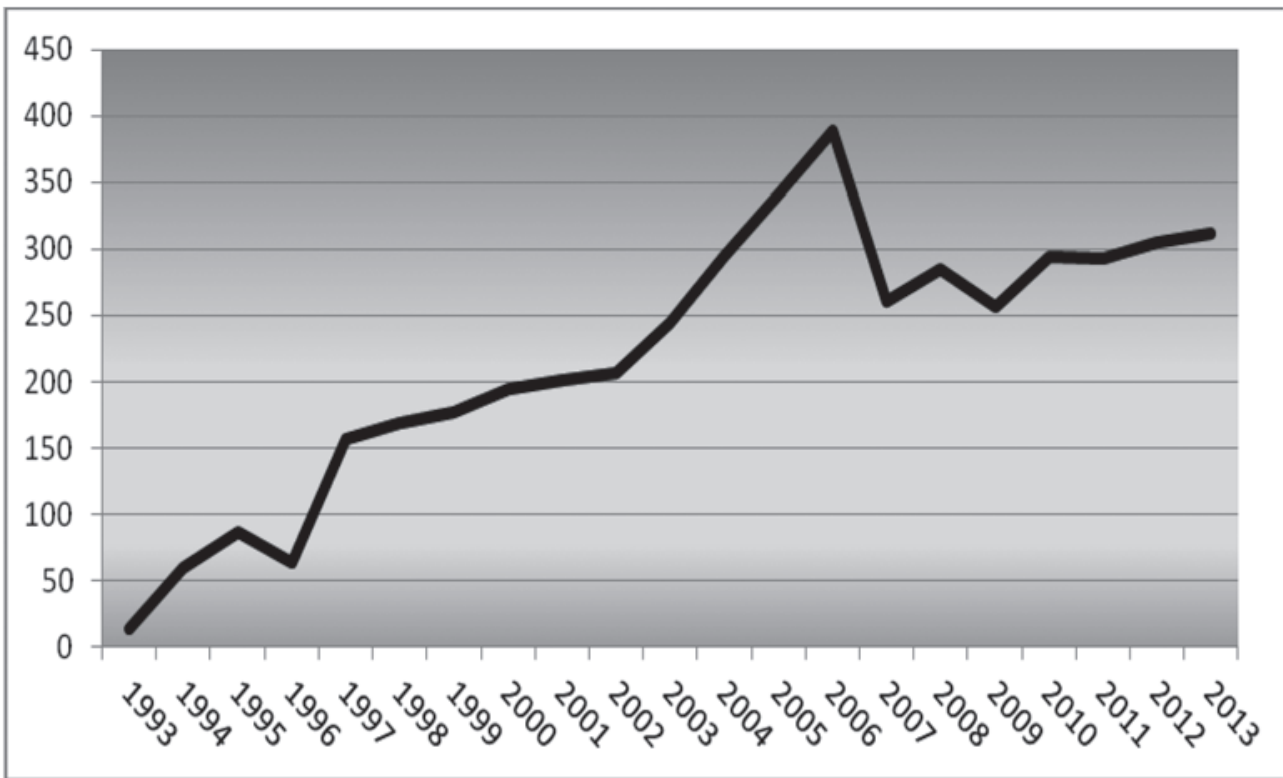

Cuadro y gráfico elaborado por la autora a partir de las siguientes fuentes:

Carga Procesal. Área de Estadística del Distrito Judicial de Lima. Elaborado por Sub gerencia de Estadística. Poder Judicial.

Libro de Ingresos Exequátur y Quejas de la 1 Sala de Familia de la Corte Superior de Justicia de Lima 2001 - 2013. 


\section{CRECIMIENTO ECONÓMICO PERUANO $2000-2013$}

\section{PBI real del Perú (en US\$ miles de millones)}

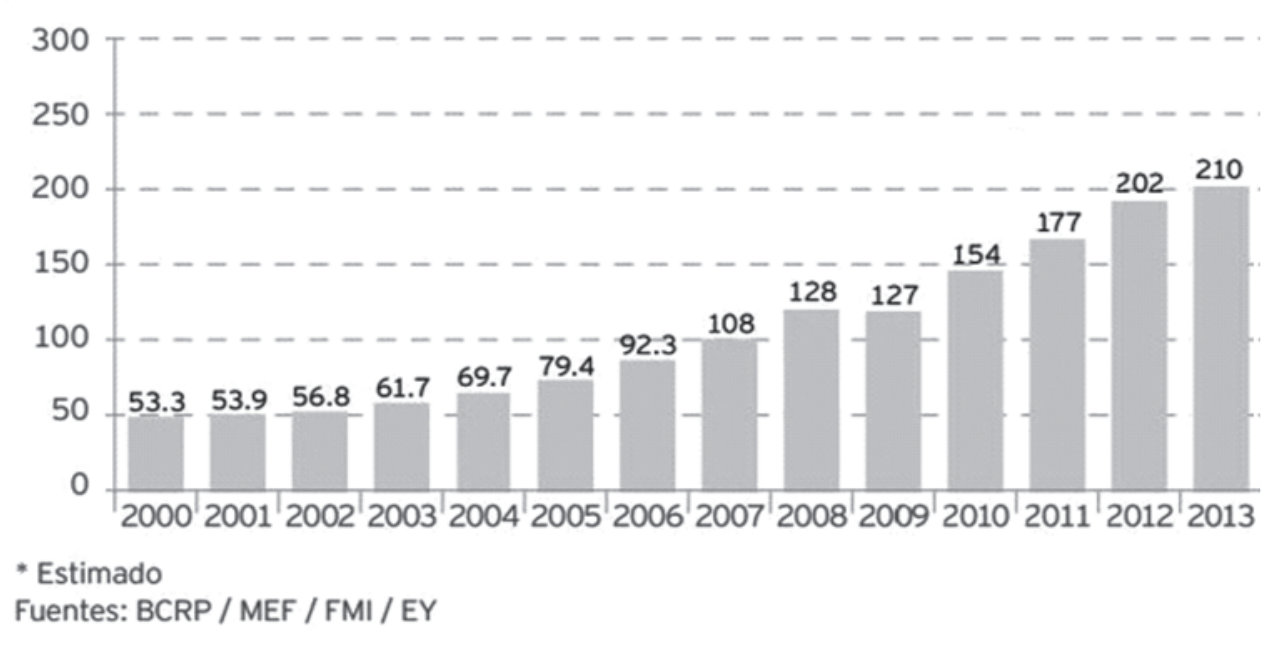

INCIDENCIA DE EXEQUATUR Vs. CRECIMIENTO ECONOMICO PERUANO

$1^{\circ} \mathrm{Y} 2^{\circ}$ Sala Especializada de Familia de la Corte Superior de Lima $2000-2013$

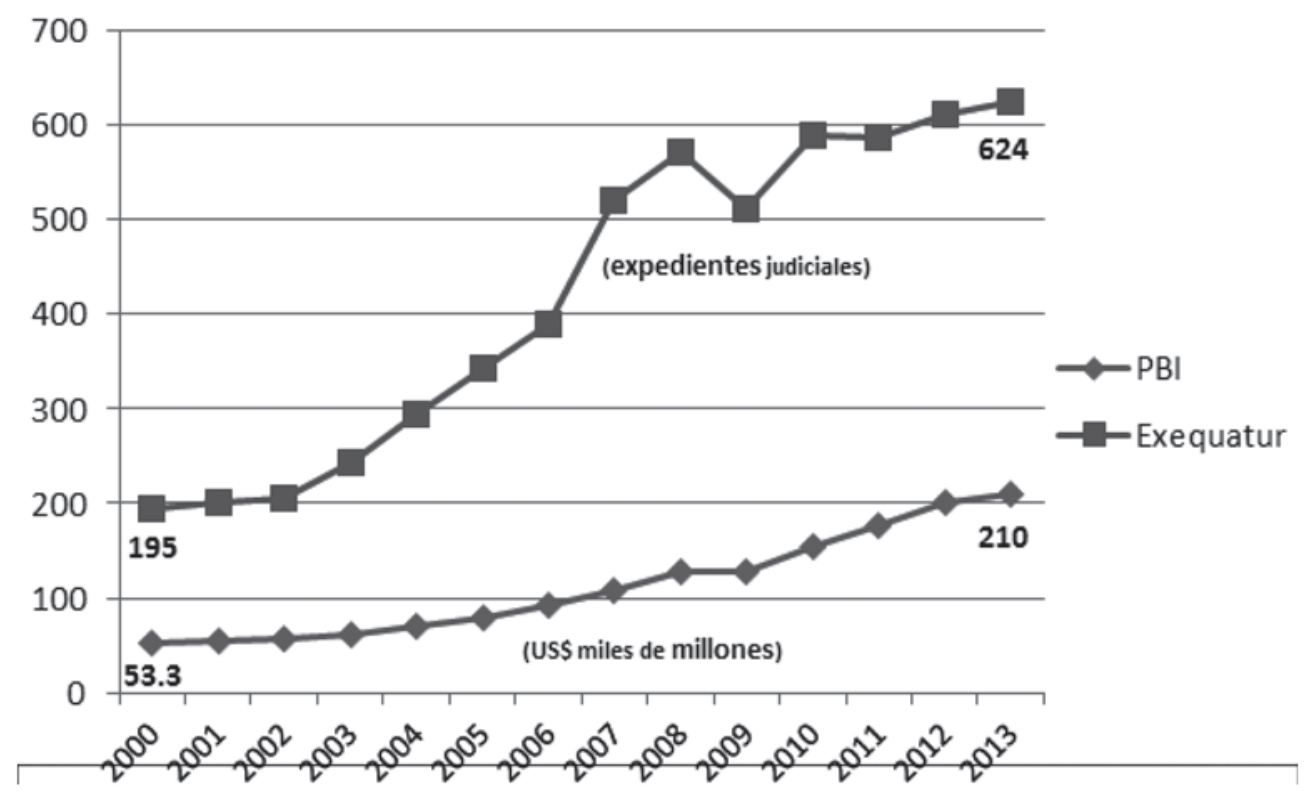


De igual modo, si lo observamos desde el escenario europeo, el proceso de integración económico y político ha estimulado aún más la movilización de personas, lo que ha llevado a esfuerzos para su tratamiento comunitario; a decir de Mercedes Sabido Rodríguez: "cambios legislativos para valorar su proyección en nuestro sistema de DIPr y en particular, su adecuación, de un lado, a las necesidades derivadas de la tutela judicial efectiva y la libertad personal $y$, de otro, a los objetivos del espacio judicial europeo"6.

Esfuerzo regulador que ha alcanzado a las relaciones matrimoniales a través de la reglamentación de la competencia judicial internacional, reconocimiento y ejecución de resoluciones judiciales en materia matrimonial y de responsabilidad parental mediante el Reglamento Comunitario 22012003, conocido como Bruselas II bis, de aplicación a los Estados miembros de la comunidad menos Dinamarca; muchos logros y también dificultades se advierten desde su vigencia, como de su precedente el Reglamento 1347/2000 Bruselas I.

En todo caso, cierto es que fuera de los alcances reglamentarios comunitarios y en consecuencia dentro del ámbito de regulación estatal de España y de los otros países europeos se encuentra el reconocimiento de sentencias extranjeras provenientes de los otros continentes, tema que como el descrito cobra interés creciente si como advertimos de las cifras reportadas, el ingreso de extranjeros extracomunitarios es cada vez mayor, situación que produce un impacto no sólo económico, social y jurídico, sino también en los tribunales, en las litigaciones referidas a determinar la eficacia extraterritorial de las decisiones extranjeras, cuya homologación formulen los migrantes o residentes extranjeros conducentes muchas veces a lograr regularizar su estatuto personal en el país.

Sabido Rodríguez, Mercedes (2013) La nueva regulación del divorcio en la unión europea. Su proyección en Derecho Internacional Privado español. En: Revista de Derecho Comunitario Europeo ISSN 1138-4026, núm. 45, Madrid, mayo/ agosto, p. 499-534. 
El impacto de la inmigración en España: Evolución global de residentes extranjeros según continente

\begin{tabular}{|r|r|r|r|r|}
\hline & \multicolumn{1}{|c|}{ AMÉRICA } & \multicolumn{1}{c|}{ ÁFICA } & \multicolumn{1}{c|}{ ASIA } & \multicolumn{1}{c|}{ TOTAL } \\
\hline $\mathbf{1 9 9 2}$ & 89.300 & 71.292 & 33.878 & 194.470 \\
\hline $\mathbf{1 9 9 3}$ & 96.836 & 79.294 & 34.907 & 211.037 \\
\hline $\mathbf{1 9 9 4}$ & 103.324 & 82.602 & 35.742 & 221.668 \\
\hline $\mathbf{1 9 9 5}$ & 108.931 & 95.725 & 38.221 & 242.877 \\
\hline $\mathbf{1 9 9 6}$ & 121.268 & 98.820 & 43.471 & 263.559 \\
\hline $\mathbf{1 9 9 7}$ & 126.959 & 142.816 & 49.110 & 318.885 \\
\hline $\mathbf{1 9 9 8}$ & 147.200 & 179.487 & 60.714 & 387.401 \\
\hline $\mathbf{1 9 9 9}$ & 166.709 & 213.012 & 66.340 & 446.061 \\
\hline $\mathbf{2 0 0 0}$ & 199.964 & 261.385 & 71.015 & 532.364 \\
\hline $\mathbf{2 0 0 1}$ & 298.798 & 304.149 & 91.552 & 694.499 \\
\hline $\mathbf{2 0 0 2}$ & 418.272 & 409.057 & 112.031 & 939.360 \\
\hline $\mathbf{2 0 0 3}$ & 530.648 & 432.662 & 121.455 & 1.084 .765 \\
\hline $\mathbf{2 0 0 4}$ & 524.928 & 472.033 & 126.376 & 1.123 .337 \\
\hline $\mathbf{2 0 0 5}$ & 835.142 & 618.843 & 166.374 & 1.620 .359 \\
\hline $\mathbf{2 0 0 6}$ & 884.837 & 673.260 & 185.629 & 1.743 .726 \\
\hline $\mathbf{2 0 0 7}$ & 1.007 .611 & 799.981 & 224.914 & 2.032 .506 \\
\hline $\mathbf{2 0 0 8}$ & 1.097 .731 & 876.572 & 255.297 & 2.229 .600 \\
\hline $\mathbf{2 0 0 9}$ & 1.210 .815 & 943.929 & 283.895 & 2.438 .639 \\
\hline $\mathbf{2 0 1 0}$ & 1.153 .918 & 974.840 & 297.327 & 1.153 .918 \\
\hline $\mathbf{2 0 1 1}$ & 1.200 .333 & 1.039 .238 & 331.89 & 2.239 .571 \\
\hline $\mathbf{2 0 1 2}$ & 1.191 .817 & 1.083 .218 & 351.440 & 2.626 .475 \\
\hline $\mathbf{2 0 1 3}$ & 1.199 .719 & 1.096 .904 & 358.051 & 1.557 .770 \\
\hline
\end{tabular}

\section{MODELOSDERECONOCIMIENTOANIVELLATINOAMERICANO Y EUROPEO}

- Modelo de Soberanía.

- Modelo de Justicia Privada.

- En el modelo de soberanía, se fija en la jurisdicción "como poder" y ve la justicia como una expresión de poder soberano del Estado. Se caracteriza por tener como principio regulador la plenitud jurisdiccional 
de los tribunales del foro, quedando relegados o excluidos la autonomía de la voluntad. Las normas de Competencia Judicial Internacional son indisponibles y se imponen a los particulares.

- De otro lado, el modelo de justicia privada se fija en la jurisdicción como función y pone el acento en la tarea de suministrar una tutela judicial efectiva interprivatos, reconoce la autonomía de la voluntad de los particulares y la configuración del principio regulador de la proximidad razonable del asunto con el foro. Test de proximidad que supone evaluar los vínculos entre las circunstancias del litigio y el órgano judicial (domicilio, residencia, nacionalidad), vínculos procesales tales como la conexidad procesal ${ }^{7}$.

Estos modelos sustentan los sistemas de reconocimiento:

- Por homologación.

- Reconocimiento incidental puro.

$1^{\circ}$ ) Reconocimiento por homologación. El reconocimiento se obtiene mediante la superación de un procedimiento ad hoc de $<<$ homologación $>>$ de la decisión extranjera. La autoridad competente del Estado requerido debe valorar si concurren los presupuestos y requisitos para conceder el reconocimiento en el marco de un procedimiento cuyo objeto principal es, precisamente, el reconocimiento de la decisión extranjera. Se trata de un proceso autónomo, distinto al proceso desarrollado en el Estado de origen y distinto al proceso en el que se hace valer la decisión extranjera.

$\left.2^{\circ}\right)$ Reconocimiento incidental puro. El reconocimiento se produce sin que sea necesario recurrir a un $<<$ procedimiento específico $>>$ de homologación de la decisión extranjera en otro país. En efecto: la resolución extrajera se invoca, se hace valer, directamente ante la autoridad del Estado receptor. Dicha autoridad controlará si la decisión extranjera cumple ciertos $<<$ requisitos de regularidad >> para obtener el reconocimiento. En caso afirmativo, la decisión extranjera solo produce efectos en el proceso en que se hace valer. La decisión extranjera no surte efectos erga omnes. [...]

Como se puede apreciar, estas modalidades tienen correlatos vigentes de aplicación. En la unión europea el Reglamento Comunitario N. 2201/2003 relativo a la competencia, el reconocimiento y la ejecución de las resoluciones

Virgos Soriano, Martín. Ob.Cit. p.54. 
judiciales en materia matrimonial y de responsabilidad parental, se adscribe en la modalidad de reconocimiento incidental puro, puesto que a pesar de no ser necesario realizar un $<<$ procedimiento específico $>>$ para hacer valer la resolución (artículo 33). La autoridad del Estado receptor será quien controlará si cumple ciertos $<<$ requisitos y condiciones de regularidad $>>$ para obtener el reconocimiento. Así el articulo 34 contempla el orden público, el no emplazamiento y no rebeldía voluntaria del demandado, la inconciabilidad con una resolución dictada entre las mismas partes en el Estado miembro requerido o con una resolución dictada con anterioridad en otro Estado miembro o un tercer estado entre las mismas partes en un litigio que tuviere el mismo objeto y la misma causa.

De otro lado, si bien se trata de convenciones de muy antigua data, estas se encuentran vigentes para un importante sector de países latinoamericanos. Es el caso de La Conferencia Internacional Americana en la Habana del 20 de febrero de 1928 o también conocido como el Código Bustamente ${ }^{8}$, prevé un sistema de reconocimiento procesal por homologación ya que el Estado requerido controlará si la ejecutoria objeto del reconocimiento se ajustan a los requisitos procesales exigidos en cuanto a la forma y el fondo, como el control de la competencia del juez de origen, los derechos de defensa del demandado o el orden público internacional. Sin entrar a valorar cuestiones de fondo como la valoración de los hechos y la aplicación del derecho al asunto, a tenor del juez del tribunal de origen que dictó la resolución.

Así, el art 423 contemplará si el procedimiento seguido en el extranjero ha sido correcto en atención a los criterios siguientes:

La competencia del juez extranjero para conocer del asunto y juzgarlo, la citación personal de las partes, el fallo no debe atentar al orden público o el derecho público del país en que quiere ejecutarse. La resolución debe ser ejecutoria en el Estado en que se dicte traducida autorizadamente por un funcionario o intérprete oficial y contener los requisitos necesarios para ser considerado como auténtico en el Estado de que proceda, y los que requiera para que haga fe la legislación del Estado en que se aspira a cumplir la sentencia.

De igual modo, el reconocimiento de sentencias extranjeras respecto al Tratado de Montevideo de 1889 se halla en el Tratado de Derecho Procesal

Son Estados parte: Bolivia, Brasil, Costa Rica, Cuba, Chile, Ecuador, El Salvador, Guatemala, Haití, Honduras, Nicaragua, Panamá, Perú, República Dominicana y Venezuela. 
internacional de $1940^{\circ}$, donde se contempla un sistema de reconocimiento procesal, mediante la homologación de las sentencias y fallos arbitrales en materias civiles y comerciales. Así, en los estados signatarios la resolución tendrá la misma fuerza que el país en que se han pronunciado, si reúne los requisitos siguientes: Que el fallo ejecutorio (autentica, traducido y legalizado) haya sido expedido por tribunal competente en la esfera internacional, que la parte contra quien se ha dictado, haya sido legalmente citada y representada o declarada rebelde, conforme a la ley del país en donde se ha seguido el juicio y que no se oponga a las leyes de orden público del país de su ejecución (art.5).

Siendo el carácter ejecutivo o de apremio de las sentencias o fallos arbitrales, y el juicio a que su cumplimiento dé lugar, serán los que determine la ley de procedimientos del Estado en donde se pide la ejecución.

Propio a su tradición, en los países latinoamericanos, la modalidad predominante es la de homologación, distinguiéndose por el sistema conflictual o procesal de acuerdo a la opción legislativa de los distintos Estados.

En el caso peruano, para apreciar el contenido de la regulación competencial internacional, consideramos necesario resaltar el importante esfuerzo legislativo que se imprimió a la normatividad sobre derecho internacional privado en el libro X del Código Civil de 1984, que en principio sistematizó de modo orgánico las normas relativas a la competencia jurisdiccional, ley aplicable y reconocimiento y ejecución de sentencias y fallos arbitrales extranjeros, las mismas que se encontraban dispersas en diversos cuerpos legales, reforma que incorporó las tendencias más innovadoras de la época, desplazando tradicionales competencias exclusivas en materia personal en razón a la nacionalidad, estableciendo reglas facultativas de las mismas, fortaleciendo el factor de conexión domicilio como criterio atributivo de competencia, en aras de otorgar un trato igualitario a nacionales y extranjeros, favoreciendo el acceso y tutela de sus derechos.

Nos remitiremos brevemente a los requisitos previstos por el Código Civil peruano para el reconocimiento de sentencias extranjeras, prevista en el Art. 2104.

Son Países integrantes y ratificantes Argentina, Brasil, Colombia, Bolivia, Paraguay, Perú y Uruguay. 
1. Que no resuelvan asuntos de competencia peruana exclusiva.

2. Que el tribunal extranjero haya sido competente para conocer el asunto de acuerdo a sus normas de Derecho Internacional Privado y a los principios generales de competencia procesal internacional.

3. Que se haya citado al demandado conforme a la ley del lugar del proceso; que se le haya concedido plazo razonable para comparecer; y que se le hayan otorgado garantías procesales para defenderse.

4. Que la sentencia tenga autoridad de cosa juzgada en el concepto de las leyes del lugar del proceso.

5. Que no exista en el Perú juicio pendiente entre las mismas partes y sobre el mismo objeto, iniciado con anterioridad a la interposición de la demanda que originó la sentencia.

6. Que no sea incompatible con otra sentencia que reúna los requisitos de reconocimiento y ejecución exigidos en este título y que haya sido dictada anteriormente.

7. Que no sea contraria al orden público ni a las buenas costumbres.

8. Que se pruebe la reciprocidad.* (modificado por el Código Procesal Civil: La reciprocidad se presume).

Los requisitos indicados son recogidos por las distintas legislaciones latinoamericanas, en tanto salvaguardan la observancia de los principios que integran el debido proceso, y el control del orden público internacional. Al respecto, queremos proponerles el examen de uno de ellos: El reconocimiento de fallos judiciales con calidad de cosa juzgada, a propósito de los divorcios no judiciales.

\section{EL RECONOCIMIENTO DE DIVORCIOS NOTARIALES $Y$ ADMINISTRATIVOS, UNA PERSPECTIVA IBEROAMERICANA.}

Presentaremos un cuadro comparativo de diversos países latinoamericanos que han incorporado estas modalidades de divorcio no judicial, que representan una tendencia en la región. 


\begin{tabular}{|c|c|c|c|}
\hline Perú & divorcio notarial & $\begin{array}{c}\text { divorcio administrativo } \\
\text { o registral }\end{array}$ & $\begin{array}{c}\text { Reconocimiento conflictual o } \\
\text { procesal }\end{array}$ \\
\hline Cuba & $\mathrm{x}$ & $\mathrm{x}$ & Procesal por homologación \\
\hline México & & $\mathrm{x}$ & Procesal por homologación \\
\hline Brasil & $\mathrm{x}$ & & Procesal por homologación \\
\hline Colombia & $\mathrm{x}$ & & Procesal por homologación \\
\hline \multicolumn{1}{|c|}{ Bolivia } & $\mathrm{x}$ & & Procesal por homologación \\
\hline Panamá & & & Procesal por homologación \\
\hline \multicolumn{1}{|c|}{ Chile } & & & Procesal por homologación \\
\hline Argentina & & & Procesal por homologación \\
\hline Costa Rica & & & Procesal por homologación \\
\hline El Salvador & & & Procesal por homologación \\
\hline Guatemala & $\mathrm{x}$ & & Procesal por homologación \\
\hline Honduras & & & Procesal por homologación \\
\hline Nicaragua & $\mathrm{x}$ & & Procesal por homologación \\
\hline $\begin{array}{l}\text { República } \\
\text { Dominicana }\end{array}$ & & & Procesal por homologación \\
\hline Uruguay & & & Procesal por homologación \\
\hline Venezuela & & & Procesal por homologación \\
\hline
\end{tabular}

\section{PLANTEAMIENTO DEL PROBLEMA:}

Las convenciones y legislaciones latinoamericanas establecen expresamente los requisitos para el reconocimiento de sentencias y laudos arbitrales extranjeros, por lo que gran parte de la jurisprudencia no considera los divorcios notariales o administrativos como susceptibles de reconocimiento y por lo tanto, no tienen efectos en el territorio de su República.

¿Esta posición importa una denegatoria de justicia y por lo tanto, la afectación al derecho a la tutela judicial efectiva de los ciudadanos que pretenden la eficacia de sus divorcios administrativos o notariales obtenidos regularmente, por procedimientos legalmente establecidos?

\section{Posiciones Jurisprudenciales}

1) Deniegan la homologación al considerar que a tenor de la legislación nacional del Estado requerido, el divorcio fue dictado por un órgano que no ejerce jurisdicción (notario público); por tanto, no puede ser apreciado como un acto jurídico expedido por una autoridad competente. En ocasiones también se excepciona el orden público nacional como causa de denegación. 
- Colombia: Corte Suprema de Justicia, Sala Civil. Sentencia no 1100102030002008-02099-00 de 8 de Julio de 2013

- Chile: Corte Suprema de Justicia de Chile, recurso no 1907/2010. Sentencia de Familia № 9064 de 25 de marzo de 2010

- Panamá:

Corte Suprema de Justicia. Ejecutoria de 14 de agosto de 2007

Corte Suprema de Justicia. Ejecutoria de 22 de febrero de 2000

- Venezuela: Juzgado Superior $2^{\circ}$ en lo Civil y Mercantil de Zulia. Decisión № 2-063-10 de 25 de marzo de 2010.

2) Admiten la homologación en base a que el ordenamiento de origen, atribuye al notario o encargado del Registro Civil facultades para declarar la disolución del vínculo, en el caso los divorcios promovidos de común acuerdo entre los cónyuges.

- Costa Rica: Sala $1^{\mathrm{a}}$ de la Corte. Sentencia № 01574. 29 de Noviembre de 2012

- Perú: Corte Suprema de la República, Sala Civil transitoria, apelación $\mathrm{N}^{\circ}$ 2254-2013. Ejecutoria de 14 de agosto del 2013

- España:

- Audiencia Provincial de Barcelona, Auto de 25 de julio de 2013

- Tribunal Supremo. Sala de lo civil. ATS de 17 de octubre de 2006, ATS de 1 marzo de 2005, ATS de 31 de julio de 2000 y ATS de 8 septiembre de 1998 .

Resulta clave para el planteamiento que vamos a proponer respecto a la homologación de divorcios administrativos y notariales que, es la magistratura la que muchas veces no amerita suficientemente los alcances territoriales de sus reglas de CJI y que en consecuencia, pretende extrapolar su regulación procesal e incluso sustantiva a la actuación y determinación de la competencia y regulación de las materias sujetas a su reconocimiento, confundiendo las técnicas de conflicto de leyes propia de la competencia judicial directa, a la aplicada en los casos de la competencia indirecta al pretender resolver las solicitudes de reconocimiento.

Calvo Caravaca, sostendrá además, que dicha regulación deberá ser compatible con los principios generales de competencia judicial internacional, que requieren la vinculación efectiva de la causa con el tribunal de origen, tema que consideramos decisivo en esta materia, en el cual insistiremos porque es el que le da legitimidad al tribunal $u$ "órgano administrativo legalmente competente" que expide la sentencia o decisión. 
Delgado Barreto afirma: "Los Estados autónomamente, o bien en virtud de tratados limitan su competencia judicial internacional, pues no pueden abocarse al conocimiento de todas las cuestiones derivadas de cualquier situación jurídica internacional que se plantee ante sus tribunales, siendo necesario que sean competentes de acuerdo a los principios generales de competencia internacional que exigen que exista una vinculación objetiva entre la relación jurídica y el tribunal."10

La jurisprudencia presentada nos permite apreciar las dos posiciones que nítidamente sustentan el tema, la tradicional, que asimilando la interpretación literal de su normativa niega de plano la posibilidad de homologación de los divorcios administrativos y notariales, en tanto no se ha seguido un proceso judicial que haya concluido con una sentencia, en calidad de cosa juzgada, no obstante considerar como se ha apreciado precedentemente, es una forma legitimada en varios de nuestros países latinoamericanos.

De otro lado, se ha homologado dichos divorcios, considerando que éste se ha realizado ante un órgano competente para conocer el asunto, de acuerdo a sus normas de Derecho Internacional Privado y a los principios generales de competencia procesal internacional, de lo que se desprende que existió un proceso que fue registrado oficialmente, asimilando sus efectos a los que produce un proceso judicial concluido.

Último argumento, que exponen de manera coincidente las ejecutorias españolas que otorgan el reconocimiento a estos divorcios. Al respecto, el primer sector podría sostener, que son admitidos teniéndose en cuenta el régimen flexible que tiene el país del divorcio, sin expresión de causa, que solo requiere que el matrimonio tenga una duración mayor de tres meses, y puede ser solicitado conjunta o unilateralmente por cualquiera de los cónyuges; al respecto, deseamos precisar que este cambio legislativo se produjo en España en el año 2005, y la posición descrita se asume en la jurisprudencia española desde el año 1998, cuando su realidad legislativa en materia de divorcio era restringida, resaltamos este aspecto porque más allá de similitudes de regulaciones de legislación consideramos que lo trascendente en esta materia son los principios que sustentan el régimen de competencia judicial internacional, como ya lo acotáramos y a los cuales debe responder el sistema judicial, en su obligación de brindar tutela jurisdiccional efectiva. Ya por 1998, con claridad se comprendía: “...el reconocimiento de la decisión extranjera no debe condicionarse a la denominación formal de su Autoridad de origen;

10 Delgado Barreto, César (2008) Introducción al Derecho Internacional Privado. Tomo III. Primera parte. Lima. p. 30-31. 
el orden público procesal español únicamente exige que dicha Autoridad haya actuado en el ejercicio de la función jurisdiccional, es decir, la que nuestro ordenamiento atribuye a los jueces y tribunales; satisfecha esta exigencia, habrá que verificar que el contenido de la decisión así adoptada tampoco vulnera la vertiente sustantiva del orden público español. La aplicación de esta doctrina legal ha llevado al Tribunal Supremo a reconocer sistemáticamente las decisiones de divorcio autorizadas por los Notarios de la República de Cuba y a denegar las otorgadas ante los Adules del Reino de Marruecos hasta 1997 con la entrada del Convenio...el Tribunal ha acuñado el concepto de «imperium», cuya concurrencia en la función de la Autoridad extranjera garantiza el respeto al orden público español en su perspectiva procesal. Entiende que no hay vulneración de éste cuando la Autoridad extranjera actúa revestida de imperium, noción que posee un contenido más amplio que el estrictamente jurisdiccional, pues comprende también los actos de naturaleza eminentemente administrativa emanados de dichos órganos"11

Pretender reconocer efectividad de estos divorcios como de los judiciales sólo por el argumento de que están contemplados en su ordenamiento jurídico, importa reducir el ámbito de discusión del reconocimiento, a otorgarlo siempre que la legislación del foro sea coincidente a la aplicada, criterio territorialista, que pretende proyectar los alcances de su regulación a lo resuelto por otros Estados, bajo interpretaciones in extenso de nociones de orden público o buenas costumbres, que en este aspecto resultan obsoletas si somos testigos del proceso de globalización en que vivimos, en el que el orden público internacional sustenta por excepción su aplicación o reconocimiento ante la afectación de derechos fundamentales del núcleo duro del ordenamiento contemplado en las Cartas Constitucionales.

Carrascosa González, puntualiza, "excepcionar la lex fori a través del orden público debe aplicarse de forma restrictiva significa que tal «orden público internacional» operará sólo y exclusivamente cuando sea estrictamente necesario rechazar la aplicación del Derecho extranjero designado por la norma de conflicto española para proteger la organización valorativa y económica de la sociedad española, y sólo en la justa medida en que sea preciso para ello." Por eso, la contrariedad debe ser claramente manifiesta, la consideración de incompatibilidad puede ser de forma parcial pues solo debe excepcionarse aquello que exclusivamente sea contrario a los principios generales de un ordenamiento jurídico. ${ }^{12}$ En conclusión, podemos considerar que la jurisprudencia latinoamericana,

\footnotetext{
11 Juárez Pérez, Pilar (2008) Reconocimiento de sentencias extranjeras y eclesiásticas por el régimen autónomo español: Tribunal Supremo a los Juzgados de Primera Instancia. 2 a edición Madrid: Colex, p.133-134

12 Carrascosa González, Javier (2008) Orden público y externalidades negativas, en Boletín №206, p . 12-13.
} 
como lo hizo en su oportunidad la Europea debe orientarse a asimilar estas modalidades de divorcio, existentes y crecientes en nuestra región, que si bien literalmente por su carácter administrativo no están comprendidas en nuestras legislaciones de reconocimiento, su legalidad y observancia de formas pre establecidas las asimilan para un tratamiento semejante; de este modo, garantizamos el derecho a la tutela jurisdiccional efectiva de los ciudadanos recurrentes, así como evitamos amparar cualquier fraude de la ley, verificando las otras exigencias de la homologación como es la vinculación entre el foro y la causa de divorcio; en el caso de marras, la vinculación del órgano que la emite y la pareja que lo solicita, a través del domicilio como criterio atributivo de competencia.

\section{A MODO DE REFLEXIÓN FINAL}

Como se ha tratado de enfatizar a lo largo de la exposición, creemos que, debe ser la protección del derecho fundamental de tutela efectiva el norte interpretativo de las reglas de competencia judicial internacional, comprender la necesidad de superar un contexto de convivencia hacia el de cooperación entre naciones, que nos ha de conducir a establecer relaciones de confianza jurisdiccional, en atención al respeto común de los tribunales a derechos universales, como: la tutela efectiva y la observancia de las garantías en el proceso, el respeto a la autonomía de los Estados y por lo tanto, de sus legislaciones internas.

El divorcio notarial o administrativo en este contexto nos ha permitido una oportunidad de reflexión acerca de los alcances de nuestros sistemas escritos particularmente el derecho internacional privado y de la labor del juez en estas materias, de interpretación, recreación y creación de derecho cuando es necesario a partir de la aplicación de principios rectores universalmente acogidos como son la tutela jurisdiccional efectiva, el debido proceso, tratamiento en igualdad a nacionales y extranjeros, entre otros, que le permitan conectarse con la realidad y conservar el vínculo de ésta con una legislación como fuente del Derecho, cuya evolución siempre es menos vertiginosa que una realidad globalizada en evolución constante. 


\section{REFERENCIAS BIBLIOGRÁFICAS}

Aguilar Benitez de Lugo, Mariano (2002) Lecciones de Derecho Procesal Civil Internacional, Universidad de Sevilla, Sevilla, p. 19.

Carrascosa González, Javier (2008) Orden público y externalidades negativas En: Boletin No 206, p . 12-13.

Delgado Barreto, César (2008) Introducción al Derecho Internacional Privado. Tomo III. Primera parte. Lima: p. 30-31.

Fernández Arroyo, Diego (2008) Aspectos esenciales de la competencia judicial internacional en vistas de su reglamentación interamericana. Disponible en internet: http://www.oas.org/dil/esp/293-326\%20 Diego\%20Fern\%C3\%A1ndez\%20A.\%20def.BIS.pdf Consultado el 20 de agosto de 2005

Juárez Pérez, Pilar (2008) Reconocimiento de sentencias extranjeras y eclesiásticas por el régimen autónomo español: Tribunal Supremo a los Juzgados de Primera Instancia. 2 a edición. Madrid: Colex, p.133-134.

Sabido Rodriguez, Mercedes (2013) La nueva regulación del divorcio en la unión europea. Su proyección en Derecho Internacional Privado español. En: Revista de Derecho Comunitario Europeo ISSN 1138-4026, núm. 45, Madrid, mayo/agosto, p. 499-534.

Virgos Soriano, Miguel (2007) Derecho Procesal Civil Internacional. Litigación internacional. Madrid: Civitas.

Fecha de recepción : 01 de agosto de 2015

Fecha de aceptación : 14 de agosto de 2015 
